\title{
C-Jun promotes cellular survival by suppression of PTEN
}

\author{
K Hettinger ${ }^{1,6}$, F Vikhanskaya ${ }^{1,6}$, MK Poh ${ }^{1}$, MK Lee ${ }^{1}$, I de Belle ${ }^{2}$, J-T Zhang ${ }^{3}$, SAG Reddy ${ }^{4}$ and K Sabapathy ${ }^{\star, 1,5}$
}

\begin{abstract}
Activation of C-Jun, a component of the AP-1 family of transcription factors, leads to either promotion or prevention of apoptosis. However, the molecular determinants of c-Jun-mediated cell survival are still unclear. We show here that inducible expression of c-Jun promotes cellular survival by negatively regulating the expression of the tumor-suppressor PTEN, resulting in the concomitant activation of the Akt survival pathway. Consistently, $c-j u n^{-1-}$ fibroblasts, which are sensitive to nutrient deprivation, and human cell lines in which c-Jun expression is silenced, express elevated levels of PTEN. siRNA-mediated silencing of PTEN resulted in the reduction of cell-death owing to c-Jun deficiency. c-Jun was found to suppress PTEN expression by binding to a variant AP-1 site found in the $5^{\prime}$ upstream sequences of PTEN promoter. Finally, an inverse correlation between c-Jun and PTEN levels was apparent in a panel of human tumor cell lines, independent of their p53 status. Together, the data demonstrate that c-Jun contributes to the promotion of cellular survival by regulating the expression of PTEN. Cell Death and Differentiation (2007) 14, 218-229. doi:10.1038/sj.cdd.4401946; published online 5 May 2006
\end{abstract}

c-Jun is an important member of the activator-protein 1 (AP-1) complex, which also include the other Jun and Fos proteins. ${ }^{1,2}$ Activation of c-Jun, primarily through phosphorylation by the C-Jun amino terminal kinases (JNKs), leads to regulation of cellular survival or cellular proliferation, and the decision appears to depend on the cell type and on the stimulating signal. ${ }^{3,4}$ Not surprisingly, c-Jun activation has been implicated in many pathological conditions. It has been shown that JNK activity is elevated, and endogenous c-Jun is highly phosphorylated in many cancers. ${ }^{5,6}$ Moreover, c-Jun phosphorylation has been associated with neuronal apoptosis in several neuro-pathological conditions including neuro-degenerative disorders. ${ }^{7,8}$ These findings, together with others, have implied an important role for the JNK/c-Jun pathway in regulating several cellular processes.

In vivo studies using genetically modified mice and cells from knockout and transgenic mice have indicated that $c$-jun is an essential gene that regulates many embryonic processes. ${ }^{9}$ Besides, c-Jun has been shown to regulate the efficient transition of the G1-Sphase of the cell cycle, ${ }^{10}$ and cells lacking c-Jun have a severe proliferation defect. ${ }^{11,12}$ In addition, it was demonstrated that $\mathrm{c}$-Jun $\mathrm{N}$-terminal phosphorylation is important for efficient cellular proliferation. ${ }^{3}$ Molecular analysis has revealed that expression of a classical AP-1 target gene, cyclin D1, which is involved in regulating cellular proliferation, is reduced in the absence of c-Jun, ${ }^{12}$ thereby identifying cyclin D1 as one c-Jun-regulated gene controlling proliferation.
Besides controlling cellular proliferation, c-Jun has been shown to promote or inhibit apoptosis in several cellular systems. ${ }^{13-19}$ Deletion of c-Jun in neurons resulted in reduced apoptosis. ${ }^{16}$ Moreover, efficient phosphorylation of c-Jun by the JNKs appear to be a critical event in the induction of apoptosis of mature neurons, as mice lacking the brainspecific JNK, JNK3, and mice carrying a mutant $c$-jun allele having the JNK phosphoacceptor Serines 63 and 73 changed to Alanines (junAA), were shown to be resistant to kainateinduced neuronal apoptosis. ${ }^{3,20}$ Furthermore, C-Jun phosphorylation appears to be essential for the JNK-mediated thymocyte apoptosis as thymocytes from junAA mice and JNK mutant mice are resistant to cell death. ${ }^{17,18,21}$ In addition, cJun appears to transduce proapoptotic signals in response to various stimuli in fibroblasts, as $c$-jun ${ }^{-1-}$ fibroblasts and jun $A A$ fibroblasts have been shown to be resistant to stress stimuli like UV irradiation and treatment with the alkylating agent, methyl methanesulfonate (MMS). ${ }^{3,15}$ Moreover, inducible expression of c-Jun was also shown to enhance cell death in fibroblasts. ${ }^{22}$ By contrast, c-Jun was also shown to inhibit apoptosis in other cellular systems. Deletion of c-Jun in hepatocytes and osteoclasts was shown to lead to increased apoptosis, partially through the network involving c-Junmediated negative regulation of p53 in hepatocytes. ${ }^{13,14}$

Molecular analysis has identified several targets for c-Junmediated apoptosis, such as Bim and FasL. ${ }^{23,24}$ However, the regulators of c-Jun-mediated survival remain to be uncovered. It is not unconceivable that c-Jun-mediated survival

\footnotetext{
${ }^{1}$ Laboratory of Molecular Carcinogenesis, Division of Cellular and Molecular Research, National Cancer Centre, 11, Hospital Drive, Singapore 169610, Singapore; ${ }^{2}$ The Burnham Institute, Cancer Research Center, 10901 North Torrey Pines Road, La Jolla, California 92037, USA; ${ }^{3}$ Department of Pharmacology and Toxicology, Indiana University School of Medicine, Indianapolis, IN 46202, USA; ${ }^{4}$ Department of Gastrointestinal Medical Oncology, The University of Texas MD Anderson Cancer Center, Houston, TX 77030, USA and ${ }^{5}$ Department of Biochemistry, National University of Singapore, 10, Kent Ridge Crescent, Singapore 119260, Singapore

${ }^{*}$ Corresponding author: K Sabapathy, Laboratory of Molecular Carcinogenesis, Division of Cellular and Molecular Research, National Cancer Centre, 11, Hospital Drive, Singapore 169610, Singapore. Tel: +65-6436-8349; Fax: +65-6226-5694; E-mail: cmrksb@nccs.com.sg

${ }^{6}$ These two authors contribution equally to this work.

Keywords: Akt; apoptosis; c-Jun; PTEN; suppression

Abbreviations: JNK, c-Jun amino terminal kinase
}

Received 11.8.05; revised 14.3.06; accepted 20.3.06; Edited by G Melino; published online 05.5.06 
mechanisms may operate in physiological conditions as well as pathological conditions such as cancer, where c-Jun expression is elevated. To address this issue, we have generated inducible cellular systems using both NIH3T3 mouse fibroblasts and $c$-jun ${ }^{-1-}$ fibroblasts in which expression of c-Jun is regulated by tetracycline, in an attempt to identify regulators of $c$-Jun-mediated survival. Our results, using these cellular systems as well as $c-j u n^{-1-}$ fibroblasts, revealed that c-Jun suppresses the expression of the PTEN tumorsuppressor gene, which is a known inducer of cellular apoptosis, ${ }^{25}$ thereby regulating the Akt/PKB survival pathway. ${ }^{26}$ Consistently, many human cancer cell lines show an inverse correlation between c-Jun and PTEN expression in a p53-independent manner. Thus, we propose that c-Jun contributes to cellular survival by regulating the expression of the tumor-suppressor PTEN.

\section{Results}

c-Jun promotes cellular survival. We have generated inducible cellular systems using both NIH3T3 mouse fibroblasts and $c$-jun ${ }^{-/}$fibroblasts in which expression of c-Jun is regulated by tetracycline. Several NIH3T3-based individual clones were isolated that showed regulated expression of c-Jun (Figure 1a). Western blot analysis of representative clones revealed that $\mathrm{c}$-Jun was inducible several folds (about 6-8 times) in clone 2 upon tetracyclinewithdrawal (Figure 1a). Comparatively, clone 15, had higher basal levels of c-Jun and tetracycline-withdrawal led to about 3- to 4-fold induction of c-Jun (Figure 1a).

Analysis of growth rates by determination of cumulative cell numbers over several days indicated that c-Jun induction led to increased cell numbers in both clones, though the difference was much more significant in clone 2 where c-Jun induction was maximal (Figure $1 \mathrm{~b}, P<0.01$ ). This c-Jundependent increase in cell growth was also confirmed in individual clones of $c$-jun ${ }^{-1-}$ fibroblasts inducibly expressing C-Jun. As previously reported, ${ }^{11,12} c$-jun ${ }^{-/}$fibroblasts grew slowly compared to cells in which c-Jun expression was induced (Figure 1c). In the presence of tetracycline, there was still some leakiness leading to expression of very low levels of c-Jun, which was not sufficient to induce a significant increase in cellular growth (Figure 1c). Thus, data from both the cellular systems indicate that enhanced expression of c-Jun leads to an increase in cellular growth.

In order to evaluate if the increased growth rates were due to increased proliferation or reduced cell death, we first analyzed the incorporation of BrdU during the S phase of the cell cycle by flow cytometry, which indicated that induction of c-Jun did not have any significant effects on cellular proliferation rates in both NIH3T3-based cell clones (Figure 1d). Hence, we analyzed the basal apoptotic rates by staining cells with propidium iodide $(\mathrm{PI})$ and Annexin- $\mathrm{V}$ FITC, which indicated that $\mathrm{C}$-Jun induction resulted in a significant and consistent decrease in basal cell death rates (uninduced versus induced: 7.2 versus $4.0 \%$ for clone 2, $P<0.01$ ) (Figure 1e). Similar results were obtained for clone 15 , as well as in $c$-jun ${ }^{-/-}$cells with inducible c-Jun expression (Figure 1e and data not shown). Together, the data suggest that c-Jun induction leads to enhanced growth owing to increased survival concomitant to reduced cell death.

c-Jun protects cells from nutrient deprivation-induced and cytotoxicity-dependent death. We next investigated if c-Jun expression would confer further resistance to cell death induced by other means. Cells were starved off nutrients (i.e. $0.1 \%$ serum in the absence of essential amino acids), which led to a significant increase in cell death of uninduced cells (Figure $2 \mathrm{a}$, left panel). However, cell death was reduced when c-Jun was induced by tetracycline removal (normal versus nutrient deprived: uninduced cells: 8.0 versus $29.7 \%$; c-Jun induced: 5.0 versus $16.6 \%$, $P<0.001$ ) (Figure 2a, left panel). Moreover, analysis of $c$ jun $^{-/-}$fibroblasts indicated that the basal cell death rate was higher and nutrient deprivation resulted in a massive increase in cell death compared to wild-type cells $\left(c-j u n^{-1-}\right.$ versus $c$-jun ${ }^{+/+}$cells: $10 \%$ medium: 13.5 versus $4.90 \%$; nutrient-deprived medium: 47 versus $24 \%, P<0.05$ ) (Figure 2a, right panel), indicating that c-Jun is required to protect against cell death during nutrient deprivation in this cellular system.

C-Jun-mediated apoptosis was shown to be dependent on de novo protein synthesis. ${ }^{19}$ As overexpression of c-Jun conferred resistance to nutrient deprivation-induced cell death, we investigated if this was due to c-Jun-dependent activation of antiapoptotic proteins or inhibition of apoptotic proteins. We rationalized that if the former were the case, inhibition of protein synthesis would lead to increased cell death in c-Jun overexpressing cells. On the contrary, if the latter were the case, there would be no effect of protein synthesis inhibition. Hence, we treated nutrient-deprived cells with cyclohexamide ( $\mathrm{CHX})$, the protein synthesis inhibitor, and analyzed cell death rates. Treatment of uninduced and nutrient-deprived cells with $\mathrm{CHX}$ led to a further increase in cell death (- versus $+\mathrm{CHX}: 26.0$ versus $61.0 \%, P<0.001)$ (Figure 2b). However, CHX treatment of c-Jun-induced cells did not result in any significant cell death (-versus $+\mathrm{CHX}$ : 18.0 versus $19.0 \%$ ) (Figure $2 \mathrm{~b}$ ). Thus, these results suggest that c-Jun probably contributed to survival by suppression of apoptotic protein expression.

In order to further evaluate if c-Jun expression could protect cells against other forms of cytotoxic stress signals, we treated the cells with hydrogen peroxide, cisplatin and sorbitol. Treatment of uninduced cells resulted in massive cell death in all cases, whereas the amount of cell death was markedly reduced when c-Jun expression was induced by withdrawal of tetracycline (Figure 2c, $P<0.05$ ). Taken together, these results indicate that the expression of $c$-Jun results in reduced cell death upon both nutrient deprivation and cytotoxic stress treatment.

c-Jun induction results in activation of Akt pathway and suppression of PTEN. The Akt/PKB signaling pathway is often implicated in survival signaling in many cellular systems. $^{26}$ We therefore investigated if c-Jun overexpression could affect this pathway. Western blot analysis indicated that phosphorylation of Akt at serine 473, which is associated with activation of Akt, ${ }^{26}$ was induced concomitant to c-Jun induction (Figure 3a). Total Akt levels were not 
a

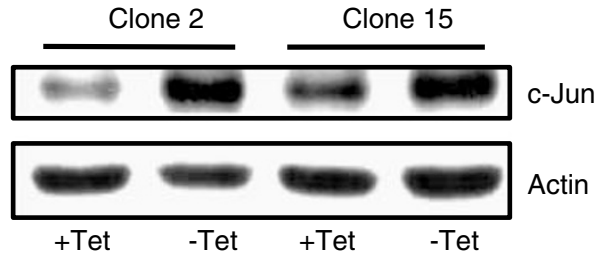

b
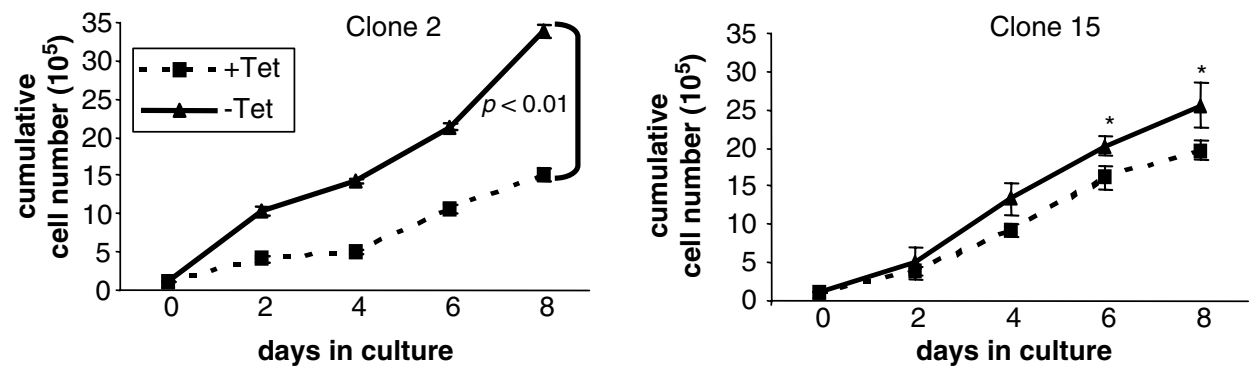

C
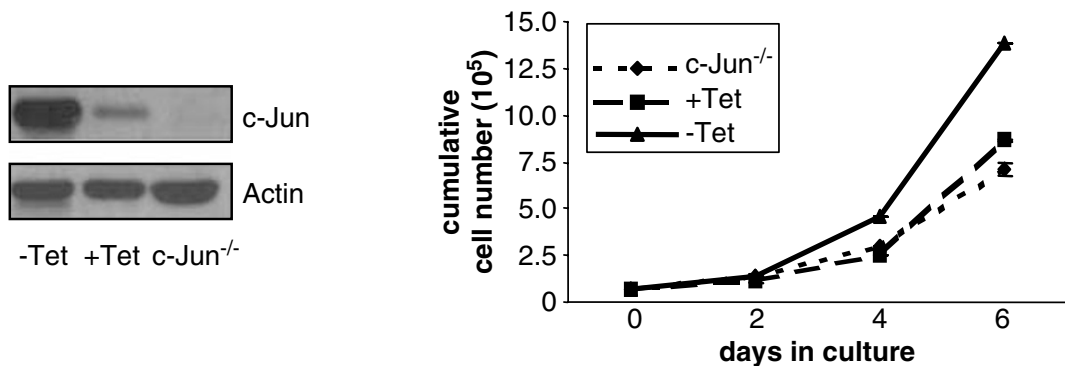

d
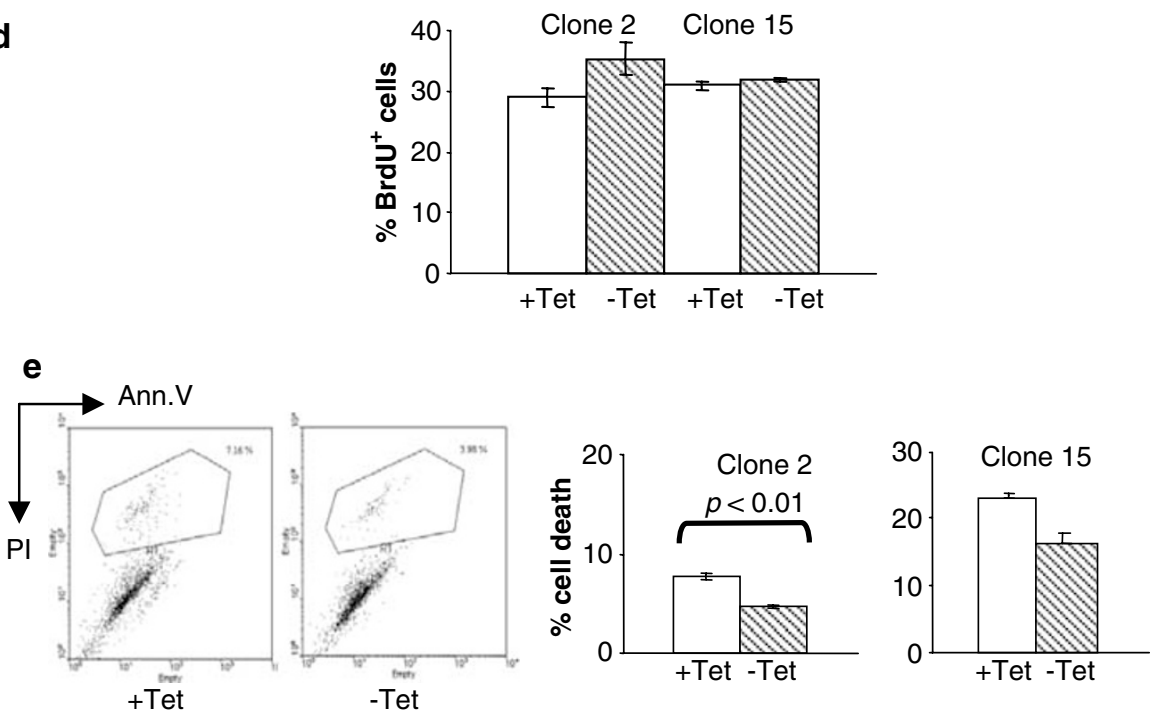

Figure 1 c-Jun promotes cellular survival. (a) Immunoblot analysis indicating expression of c-Jun in two individual NIH3T3-based clones (please see text for details) upon tetracycline withdrawal for $48 \mathrm{~h}$. c-Jun is induced upon tetracycline withdrawal (-Tet). Actin expression shows loading control. (b) Growth curves. Both clones were grown for the indicated period in the absence or presence of tetracycline and cumulative cell numbers were determined. ${ }^{*}$ indicates statistically significant difference $(P<0.01)$. (c) Inducible cell clone generated from $c-j u n^{-/-}$fibroblasts. Immunoblot analysis shows levels of c-Jun upon tetracycline withdrawal and in the presence of tetracycline in $c$-jun ${ }^{-/-}$ cells expressing the c-Jun inducible construct. $c$-jun ${ }^{-1}$ cells expressing the empty inducible construct is shown on the right-most lane (left panel). Growth curve of these cells, determined as described above, are shown on the right panel. (d) Cells were grown for $48 \mathrm{~h}$ in the absence or presence of tetracycline before being labeled for $1.5 \mathrm{~h}$ with BrdU. Subsequently, the percentage of $\mathrm{BrdU}^{+}$cells, which represent proliferating cells, was determined by flow cytometric analysis. (e) Representative data showing basal apoptotic rates, evaluated by staining with PI ( $y$ axis) and Annexin-V FITC ( $x$ axis), after $48 \mathrm{~h}$ of c-Jun induction are shown and compared to uninduced cells from clone 2 (left panel). Dots represent individual events (cells), from a population of 10000 events analyzed. Right panel show average values from three independent experiments using both clones $(P<0.01)$. All experiments described above were performed at least three independent times and error bars are indicated 

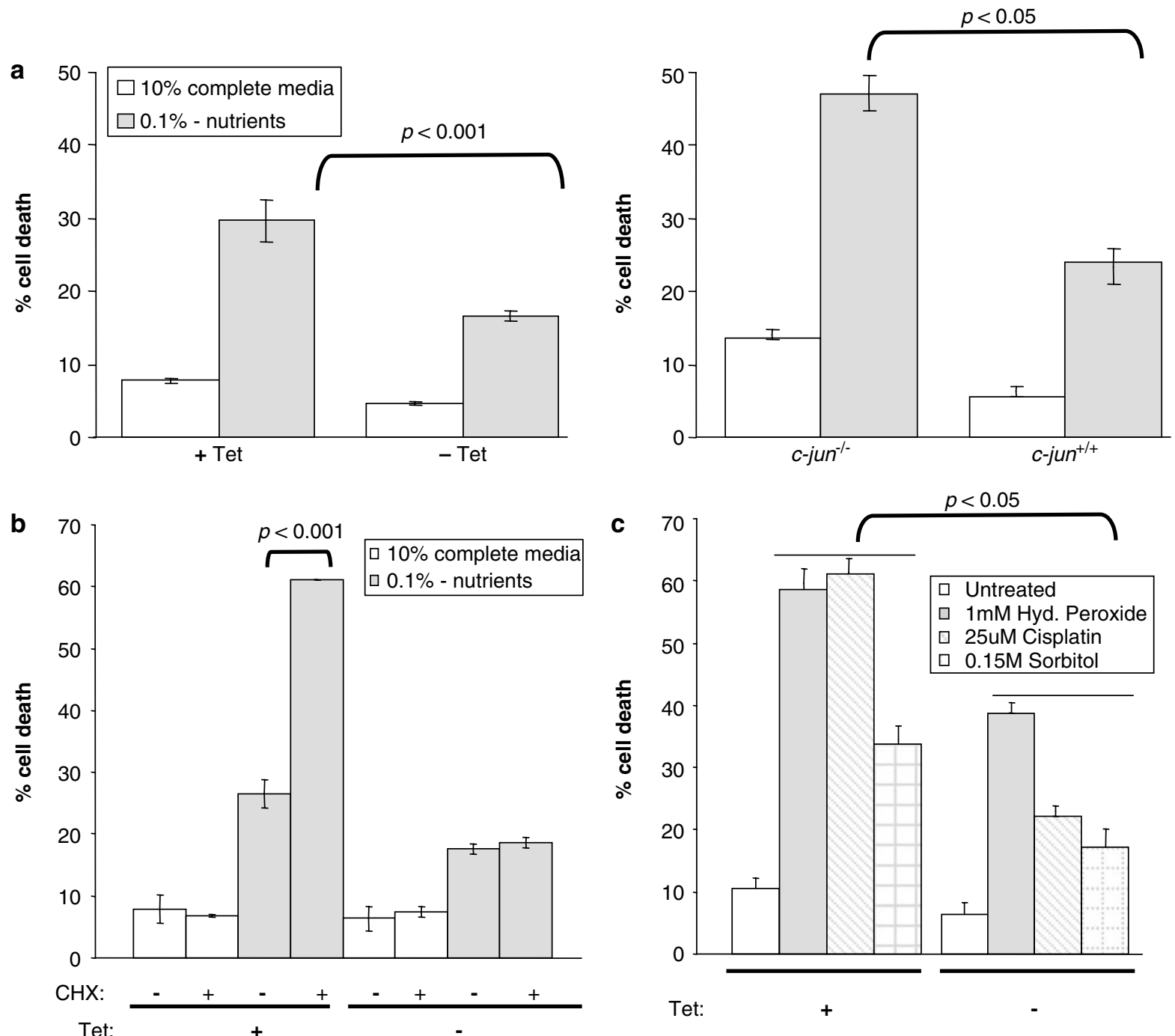

Figure 2 c-Jun protects cells from nutrient deprivation and stress-induced cell death. (a) Cell death was determined $48 \mathrm{~h}$ after tetracycline withdrawal in complete (10\%) or nutrient-deprived ( $0.1 \%$ nutrients) media, as described in legends to Figure 1e (left panel). c-Jun induction by tetracycline withdrawal results in reduced cell death. Right panel shows cell death levels in $c-j u n^{-1-}$ cells and wild-type cells $\left(c-j u n^{+/+}\right)$cultured in complete medium and upon nutrient deprivation. $c-j u n^{-l-}$ cells were found to be more sensitive to nutrient deprivation. $P$-values are indicated. (b) Cell death was determined using cells grown in complete medium (10\%) or after nutrient depletion, as described above, in the presence or absence of $1 \mu \mathrm{g} / \mathrm{ml} \mathrm{CHX}$, which was added $48 \mathrm{~h}$ before harvesting the cells. $P$-values are indicated. (c) c-Jun induction protects cells from stressinduced death. Cell death was determined $48 \mathrm{~h}$ after tetracycline withdrawal in complete $(10 \%)$ media, in the absence or presence of the indicated stress signals. Cells were treated with hydrogen peroxide, cisplatin or sorbitol, at the time of tetracycline removal

altered, indicating that the increased phosphorylation was due to a post-translation modification of Akt. In order to assess if the downstream mediators of Akt are also activated by c-Jun induction, we evaluated the status of FKHR, mTOR and Bad. c-Jun induction also resulted in an increase in the phosphorylation of FKHR at ser 256, mTOR at ser 2481 and Bad at ser112 (Figure 3b). The data thus suggest that the Akt survival pathway is activated by c-Jun induction.

We further evaluated if Akt phosphorylation is affected by the absence of c-Jun. Comparison of $c-j u n^{-/-}$fibroblasts with those stably expressing c-Jun grown in $0.1 \%$ nutrientdeprived medium indicated that the lack of c-Jun led to a marked decrease in the levels of phosphorylated Akt (Figure 3c). Release of $c-j u n^{-/-}$cells into $10 \%$ serum containing medium resulted in a mild increase in Akt phosphorylation, which was already saturated in cells expressing c-Jun (Figure 3c). Together, these data suggest that expression of c-Jun results in the activation of the Akt survival pathway, thereby probably contributing to survival.

As Akt phosphorylation and hence, activation, is negatively regulated by the PTEN tumor-suppressor gene product, ${ }^{25}$ we examined if c-Jun induction would affect PTEN levels. Analysis of PTEN mRNA levels by semiquantitative reversetranscriptase (RT)-PCR indicated that concomitant to c-Jun induction, the levels of PTEN mRNA was reduced (Figure $3 \mathrm{~d}$ ). To further confirm this effect, we compared the levels of PTEN mRNA and protein between wild-type and $c$-jun ${ }^{-/-}$fibroblasts (several clones), which indicated that absence of c-Jun led to 
a

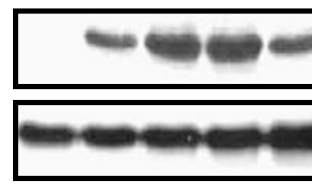

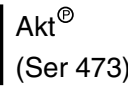

Akt
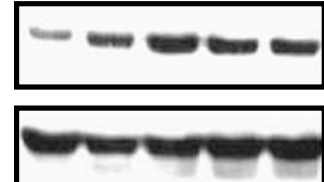

Actin

Time after c-Jun

induction (hr): $0 \quad 4 \quad 10 \quad 24 \quad 48$ b

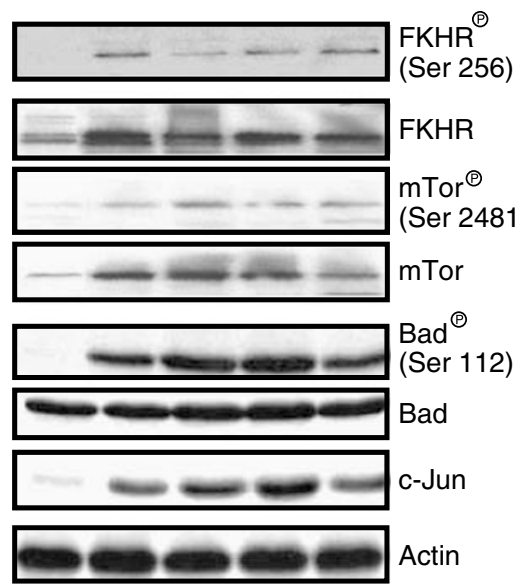

C

$0.1 \% \quad 10 \% \quad 0.1 \% \quad 0 \% \quad:$ Serum
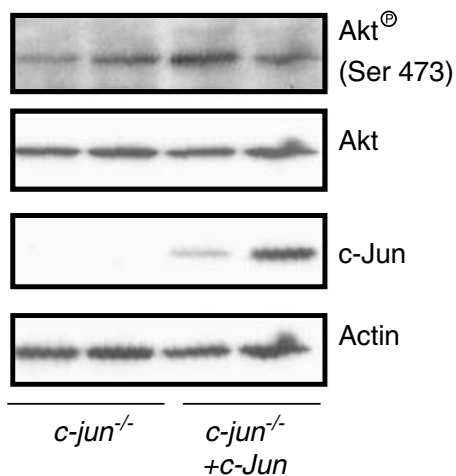

Time after c-Jun

induction (hr):0 $\quad 4 \quad 10 \quad 24 \quad 48$

d

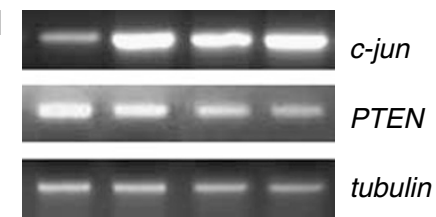

Time after c-Jun

induction (hr): $\quad \begin{array}{llll}0 & 4 & 24 & 48\end{array}$

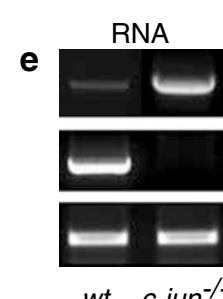

wt $\quad c-j u n^{-/-}$

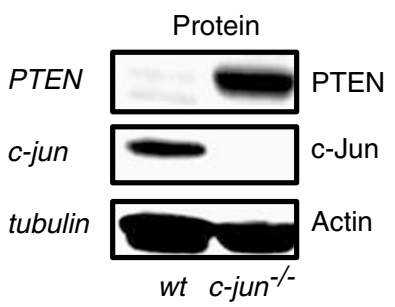

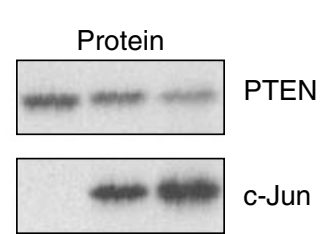

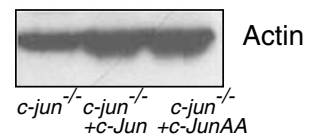

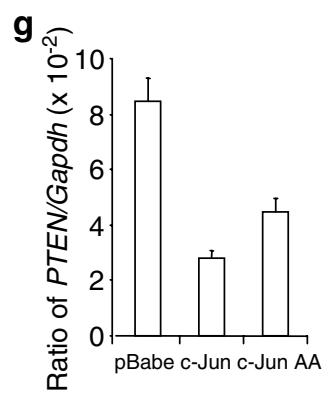

h $\mathrm{CHX}:-+++$
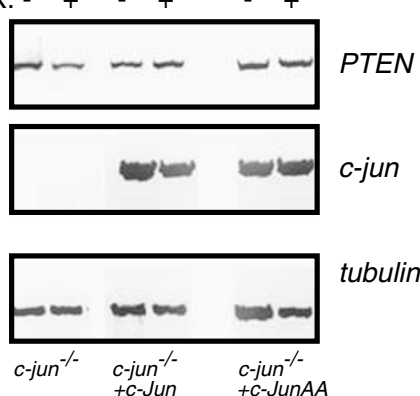

\section{i}

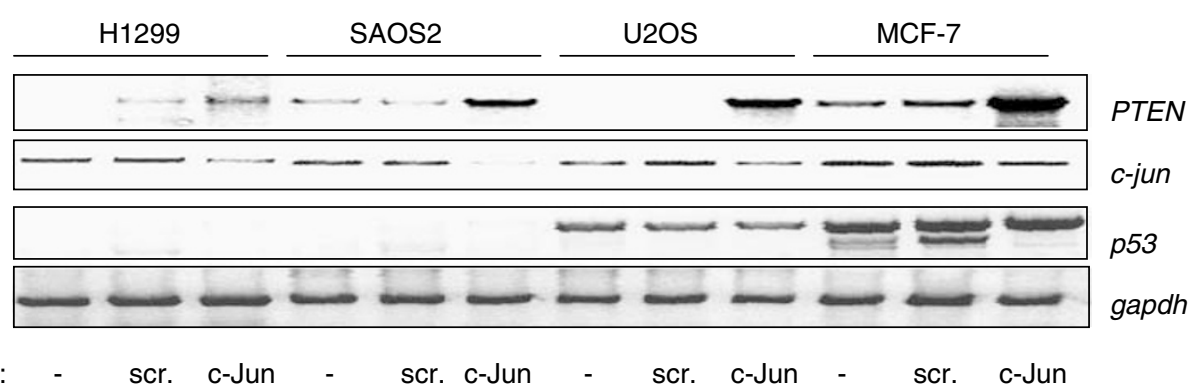

Figure 3 c-Jun induction results in activation of Akt survival pathway and suppression of PTEN. (a) Immunoblot analysis showing status of phospho-Akt (serine 473) and Akt after c-Jun induction (upon tetracycline withdrawal) for the indicated time periods in the NIH3T3-based clone 2. Actin expression shows loading control. (b) Similar immunoblot analysis showing the status of phospho-FKHR (serine 256) and FKHR, phospho-mTOR (serine 2481) and mTOR and phospho-Bad (serine 112) and Bad, after cJun induction for the indicated time periods. (c) Status of phospho-Akt (serine 473) and Akt was determined in c-jun ${ }^{-1-}$ cells and $c$-jun ${ }^{-1-}$ cells stably expressing the c-Jun (in $c$-jun ${ }^{-1-}+c$-Jun), cultured in complete medium ( $10 \%$ serum) or in nutrient-deprived medium $(0.1 \%)$ for $48 \mathrm{~h}$. Levels of c-Jun and Actin are also shown. (d) PTEN mRNA levels were determined by semiquantitative reverse transcriptase-PCR analysis, after c-Jun induction for the indicated time periods. (e) Immunoblot and semiquantitative reverse transcriptase-PCR analysis shows higher basal levels of PTEN in jun ${ }^{-1-}$ cells compared to wild-type (wt) cells. (f) Immunoblot and semiquantitative reverse transcriptase-PCR shows that stable expression of c-Jun or the phospho-mutant c-Jun (ser63ala,ser73ala: JunAA) in jun ${ }^{-1}$ cells leads to reduction of PTEN levels. (g) Levels of PTEN mRNA were determined in the above cells by real-time quantitative RTPCR, and data are represented as ratio of PTEN/GAPDH. (h) The above cells were treated without (-) or with $(+) \mathrm{CHX}(1 \mu \mathrm{M})$ for $9 \mathrm{~h}$ and the levels of PTEN was determined by reverse transcriptase-PCR as described above. (i) PTEN mRNA levels were determined by reverse transcriptase-PCR in the following human cell lines: H1299 and SAOS2 (p53 null) and U2OS and MCF7 (p53 positive), without or after transfection with control scrambled siRNA (scr) or c-jun-siRNA. Levels of c-jun and p53 are also shown 
a dramatic increase in PTEN mRNA and protein levels (Figure $3 e$, showing representative data). Furthermore, stable reintroduction of wild-type and phospho-mutant (ser63Ala, ser73Ala: referred to as JunAA) c-Jun into $c$-jun ${ }^{-/-}$cells led to a decrease in PTEN expression (both mRNA and protein), indicating that $\mathrm{C}$-Jun is indeed involved in PTEN regulation, independent of its phosphorylation status (Figure 3f). This was further confirmed by real-time quantitative RTPCR (Figure 3g).

As lack of c-Jun led to elevated PTEN mRNA levels, we next ascertained if this effect could also be due to posttranscriptional events. To this end, $c$-jun ${ }^{-1-}$ cells and $c$-jun ${ }^{-/-}$ cells stably expressing wild-type c-Jun or JunAA were treated with the protein synthesis inhibitor, $\mathrm{CHX}$. $\mathrm{CHX}$ treatment did not cause a decrease in PTEN mRNA levels in cells expressing c-Jun or JunAA (Figure $3 \mathrm{~h}$ ), indicating that $\mathrm{c}$ Jun-mediated PTEN regulation occurred at the transcriptional levels. Moreover, PTEN levels were slightly reduced in $c-j u n^{-/-}$ cells upon $\mathrm{CHX}$ treatment, suggesting that there may also be other c-Jun-independent mechanisms regulating PTEN expression.

Finally, we evaluated if p53 has any role in c-Jun-mediated regulation of PTEN expression, as PTEN is a known target of p53 ${ }^{27}$ and p53 expression is suppressed by c-Jun. ${ }^{11}$ siRNAmediated silencing of c-Jun in p53 null human H1299 (lung cancer) and SAOS2 (osteosarcoma) cells and p53 positive U2OS (osteosarcoma) and MCF-7 (breast cancer) cells resulted in an increase in PTEN mRNA levels, irregardless of the p53 status (Figure 3i). Hence, these data together suggest that $c$-Jun negatively regulates PTEN expression independent of p53 and in a transcription-dependent manner.

c-Jun regulates PTEN expression through the variant AP-1 site (PF-1). The plausible mechanism of regulation of PTEN expression by c-Jun was next examined. To this end, the $2 \mathrm{~kb}$ human PTEN promoter fragment containing both $\mathrm{AP}-1$ and p53 binding sites were used in transient transfection experiments and subsequent luciferase reporter assays. The PTEN promoter construct contains at least two potential AP-1/AP-1-like binding sites at -1912 and -438 (relative to transcription start site) ${ }^{28}$ (Figure $4 a$ ). As shown in Figure 4b, expression of c-Jun did not affect PTEN promoter activity, whereas expression of p53-induced PTEN promoter activity. The minimal PTEN promoter lacking the AP-1 or p53 binding sites, but which has been shown to retain full activity in response to UV irradiation or Egr-1 expression, $^{28}$ was also not induced by c-Jun or p53 (Figure 4b). We therefore analyzed the effect of c-Jun expression on the long $5^{\prime}$-UTR sequences of PTEN, which has been demonstrated to severely inhibit translation of PTEN and a heterologous gene firefly luciferase gene. ${ }^{29}$ Expression from the 828-1 fragment or the shorter D828479 fragments, which contain a putative AP-1 as well as SP1-binding sites, was not affected by C-Jun or SP-1 expression (Figure 4c). Moreover, expression from the D828-257 fragment, which lacks the putative AP-1 site and the SP-1, was not affected by c-Jun expression, although it was activated by the expression of SP-1 (Figure 4c). These data together suggests that $\mathrm{c}$-Jun does not suppress PTEN promoter activity through the classical AP-1-binding sites.
Alternate possibilities were thus examined. c-Jun was demonstrated to suppress $p 53$ promoter activity through a variant $A P-1$ site - known as the PF-1 site. ${ }^{11}$ Thus, we searched the PTEN $5^{\prime}$ flanking sequences for potential PF-1 sites. A single PF-1 site was found about $19 \mathrm{~kb}$ away from the transcription start site in the human PTEN $5^{\prime}$ flanking sequences (Figure 4a). Computer-based comparison indicted that the rat, mouse, drosophila and fugu PTEN $5^{\prime}$ flanking sequences also contained this PF-1 sites (Figure 4d). There was a considerable degree of homology in the flanking sequences around the PF-1 site among the various species (Figure $4 d$ ). We thus generated a $10 \times$ PF1PTEN site containing synthetic construct driving the luciferase gene and analyzed the effect of c-Jun on its activity (referred to as $10 \times \mathrm{PF}-1$ ) (Figure $4 \mathrm{a}$ ). While the $2 \mathrm{~kb}$ PTEN promoter was not affected by c-Jun expression, the $10 \times$ PF1-driven luciferase activity was consistently suppressed by c-Jun expression (PTEN promoter: vector versus c-Jun: 31 versus 30; 10xPF-1: vector versus c-Jun: 104 versus $61, P<0.05$ ) (Figure $4 \mathrm{e}$ ), suggesting that $\mathrm{C}-\mathrm{Jun}$ could suppress PTEN expression via this PF-1 site. Hence, we next evaluated if $\mathrm{c}$-Jun was able to bind to this site. Electromobility-shift analysis (EMSA) using the DNA sequences containing the PTEN-PF-1 site as a probe indicated specific binding and retardation of probe migration, only in lanes containing nuclear extracts from cJun-induced cells (by removal of tetracycline), in contrast to extracts from the unstimulated cells (Figure 4f, left panel). This binding was specific as it was competed out by specific cold competitor sequences (SC) and not by nonspecific cold competitor sequences (NSC). Moreover, addition of antibodies against c-Jun but not an unspecific antibody resulted in a supershift of this specific binding, resulting in a further retardation of probe migration (Figure 4f, left panel, see $^{*}$. In addition, induction of c-Jun did not result in any specific retardation of a nonspecific SP-1 probe in the presence of the c-Jun antibody (Figure $4 f$, left panel). We further compared extracts from wild-type and $c-j u n^{-1-}$ cells that have been cultured in $10 \%$ serum or in nutrient-deprived medium $(0.1 \%)$. Wild-type cells cultured in complete medium exhibited strong binding to the PF-1 sequences, whereas nutrient deprivation resulted in a marked decrease in binding activity (Figure 4f, right panel). By contrast, specific binding was almost abolished in $c$-jun ${ }^{-1-}$ cells cultured in complete medium (Figure 4f, right panel). Together, the data suggests that c-Jun may contribute to PTEN suppression through the PF-1 site on the PTEN $5^{\prime}$ flanking sequences.

Silencing of PTEN expression in $\mathrm{c}_{-}$jun $^{-/-}$cells results in reduction of cell death. We next investigated if relief of c-Jun-mediated PTEN suppression was contributory to enhanced cell death in $c$-jun ${ }^{-/}$cells. To this end, the effect of silencing PTEN expression (through siRNA mediated-inhibition) in $c$-jun ${ }^{-1-}$ cells on cell death was determined after nutrient depletion. Whereas transfection of scrambled control siRNA did not affect PTEN levels, PTEN siRNA markedly inhibited PTEN RNA and protein levels in $c_{\text {-jun }}{ }^{-1}$ cells, indicating that the PTEN siRNA was effective (Figure 5a). Silencing of PTEN expression in cells cultured in $10 \%$ serum-containing complete medium did not alter the 


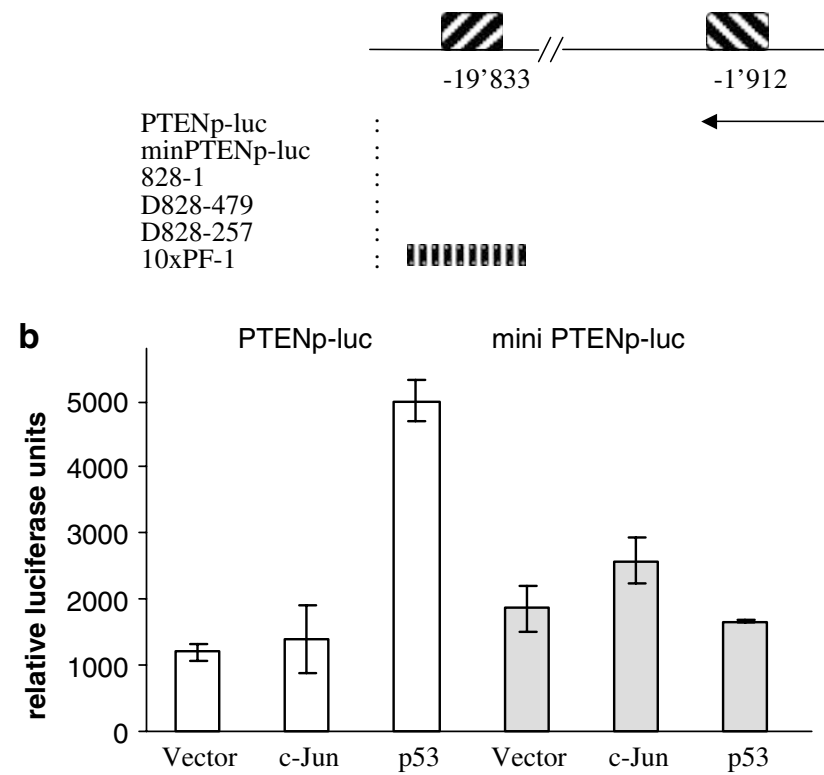

\section{d Species}

Homo sapiens

Mus musculus

Rattus norvegicus

Drosophila melanogaster

Fugu rubripes
Number of PF1-PTEN sites

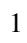

4

4

1

1

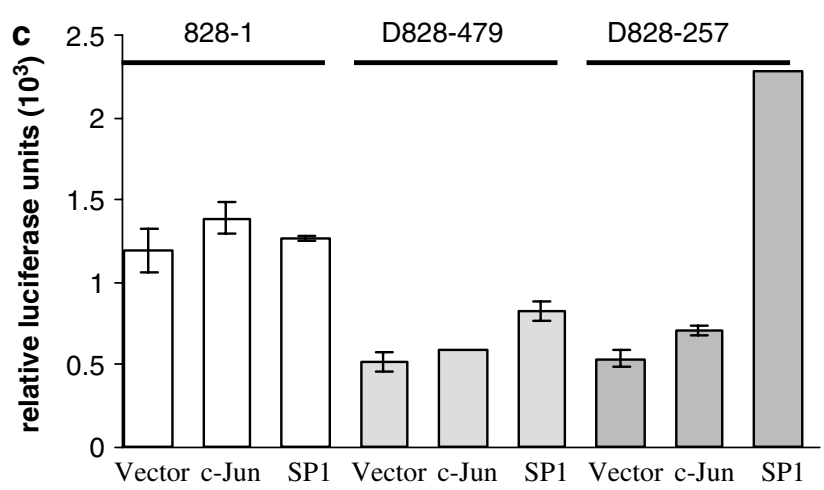

Position relative to transcription start

$-19833$

$-25710,-16269,-12383,-7845$

$-16512,-15970,-8884,-7443$

$-12658$

$-4959$

PF1

Homo sapiens -19833

Mus musculus-25710

Mus musculus-12383

Rattus norvegicus-16512

Rattus norvegicus-15970

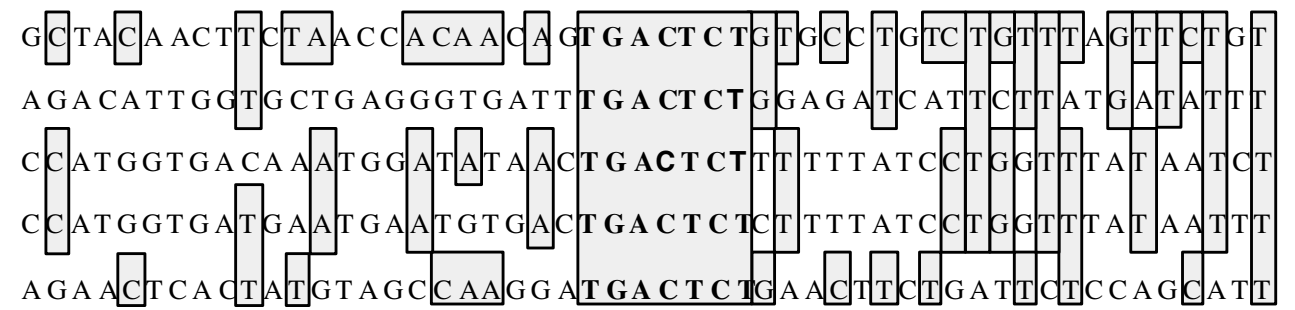

Figure 4 c-Jun regulates PTEN expression through the variant AP-1 site (PF-1). (a) Schematic diagram of PTEN promoter and genomic locus showing the various constructs used in this study and the relative positions of the various transcription factor-binding sites. Nomenclature of the luciferase reporter constructs used are shown below. The $10 \times$ PF-1 construct is a synthetic construct containing $10 \times$ PF- 1 site from the PTEN 5' sequences, as shown. (b) Relative luciferase activity from the PTEN promoter (PTENp-luc) or the minimum PTEN promoter construct (mini PTENp-luc) was determined in $\mathrm{H} 1299$ cells in the presence of the indicated expression vectors $48 \mathrm{~h}$ after transfection. All experiments were performed at least three independent times and error bars are indicated. (c) Relative luciferase activity from the $5^{\prime}$-UTR sequences from the PTEN gene (828-1) and deletions thereof (D828-479) and (D828-257) was determined as described above, in H1299 cells. (d) Number of PF1-PTEN sites found in the $5^{\prime}$ PTEN flanking regions in different species. The regions around the human PF1 site was aligned with mouse and rat regions containing the PF1-PTEN sites, and the homologous regions to human sequences are shaded (lower panel). The numbers indicate the relative location with respect to the transcription start site. The 7bp PF1-binding sequence (TGACTCT) is marked in bold. (e) Luciferase activity from the PTEN promoter construct (PTENp-luc) or the multimerized $10 \times$ PF1-PTEN site $(10 \times$ PF1) construct was determined in the presence or absence of c-Jun expression plasmid, as described above. $P<0.05$. (f) Electromobility shift assays using nuclear extracts from uninduced ( + Tet) or c-Jun induced (-Tet) cells were performed with the PF-1 sequence from the PTEN locus as a probe or an irrelevant SP-1 probe (left panel). Arrow indicates specific

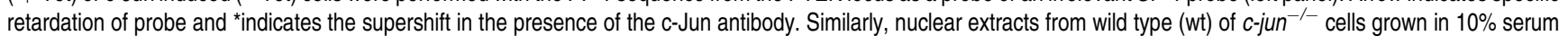
containing medium or nutrient-deprived medium ( $0.1 \%$ serum) were used as described (right panel). SC: specific competitor; NSC: nonspecific competitor; unspec. AB: unspecific antibody

basal cell death levels in both wild-type and $c$-jun ${ }^{-/}$cells (Figure 5b). However, although nutrient depletion-induced cell death was not significantly affected by scrambled siRNA expression, expression of PTEN siRNA consistently reduced the amount of cell death in $c$-jun ${ }^{-/}$cells (scrambled siRNA versus PTEN siRNA: 63 versus $46 \%, P<0.01$ ) (Figure $5 b$ ). 

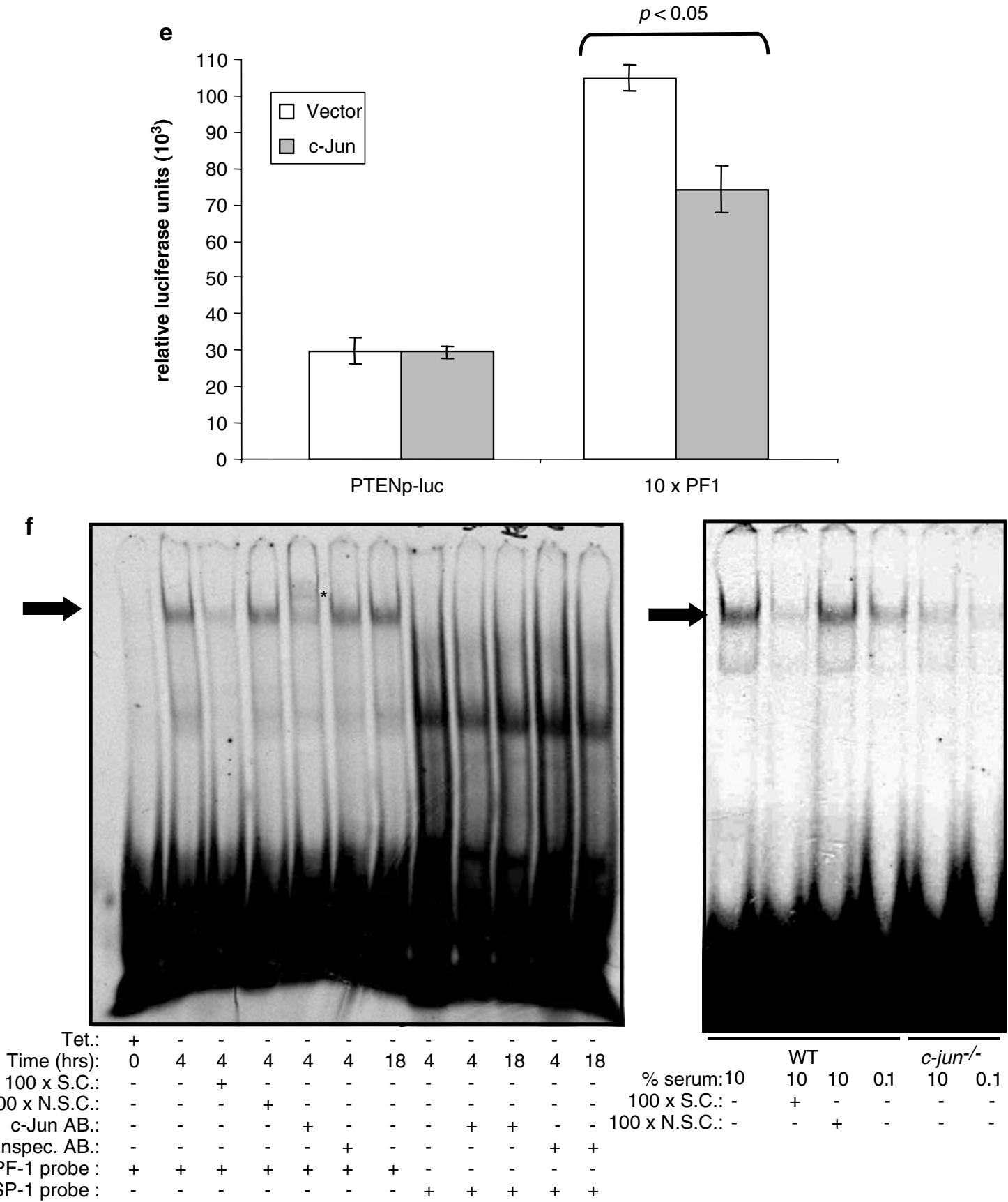

Figure 4 Continued

The level of cell death of $c$-jun ${ }^{-1-}$ cells in the presence of PTEN siRNA was around the levels found in wild-type cells depleted of nutrients (scrambled siRNA versus PTEN siRNA: 32 versus $37 \%$ ), suggesting that the increased cell death in $c-j u n^{-1}$ cells may be due at least in part to enhanced PTEN expression.

Inverse correlation between c-Jun and PTEN levels and survival in cancer cell lines. The existence of any correlation between c-Jun and PTEN levels in human cancer cells was next analyzed. As PTEN is often deleted or silenced owing to methylation in cancer cells, we selected several pancreatic cell lines (Panc-48, AsPC-1, Capan-1 and MiaPaCa-2), a glioblastoma cell line (U251) and the transformed kidney epithelial cell line (HEK293), in which PTEN was not mutated or affected by methylation but expressed varying levels of PTEN. ${ }^{30}$ Immunoblot analysis indicated that cell lines that expressed high levels of $c$-Jun had undetectable or reduced levels of PTEN (MiaPaca-2, U251 and HEK293) (Figure 6a). By contrast, cell lines that expressed undetectable levels of $\mathrm{c}$-Jun 
a

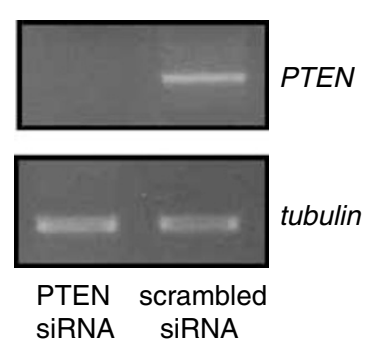

b

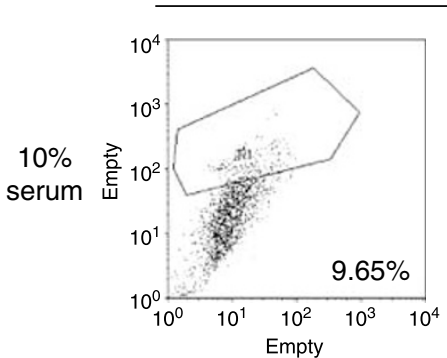

wt
Protein

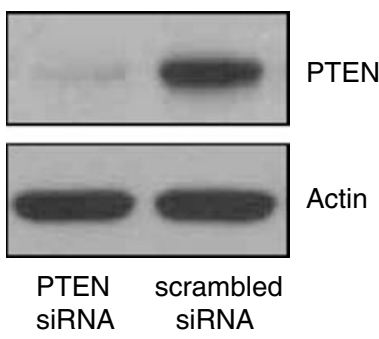

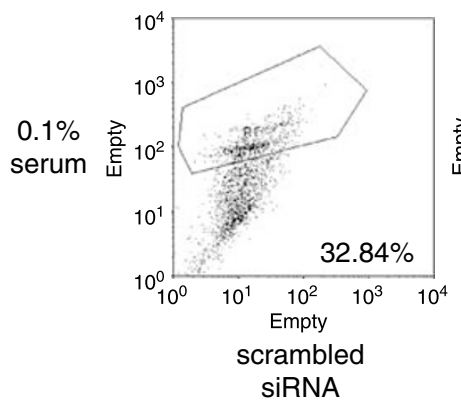
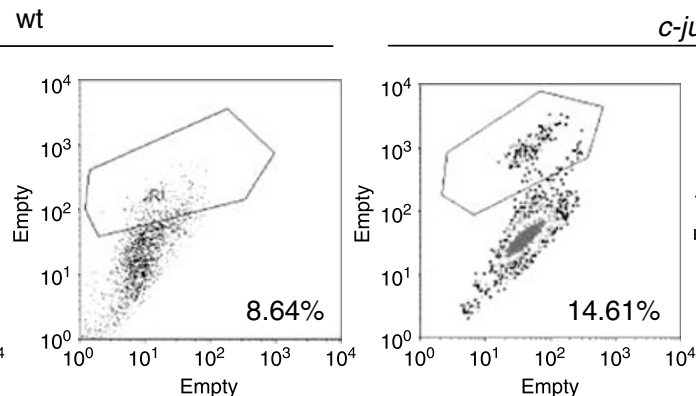

$c-j u n^{-/-}$
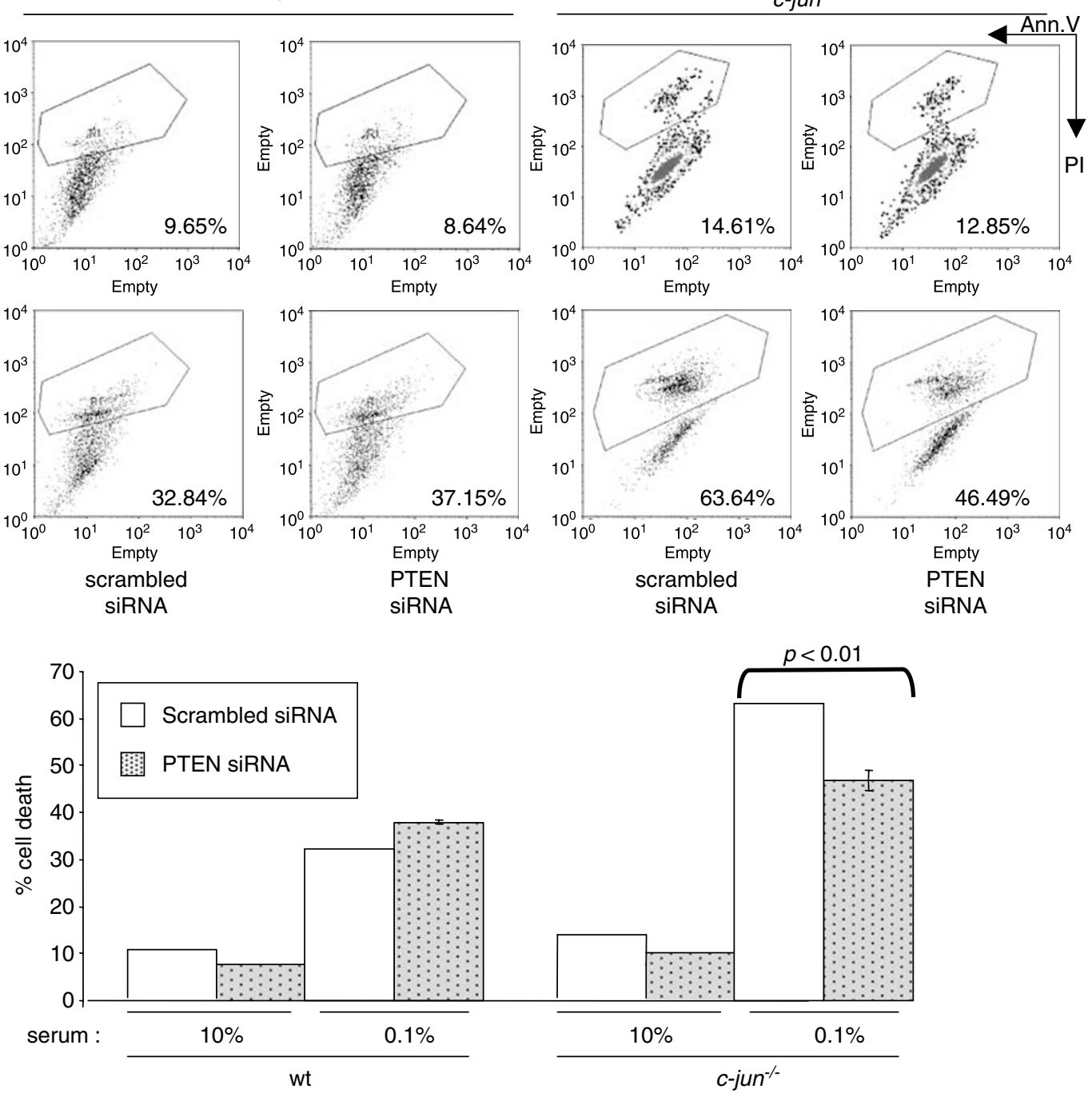

Figure 5 Silencing of PTEN expression in $c$-jun ${ }^{-1}$ cells results in reduction of cell death. (a) Semiquantitative reverse-transcriptase-PCR and immunoblot analysis indicates that siRNA-mediated silencing of PTEN results in reduction of PTEN levels in $c$-jun ${ }^{-1-}$ cells. (b) Representative data showing cell death rates, evaluated by staining with PI (y axis) and Annexin-V FITC ( $x$ axis), in wild type (wt) and $c-j u n^{-1-}$ cells that were cultured in complete medium (10\% serum) or nutrient depleted medium $(0.1 \%$ serum) in the presence of scrambled control siRNA or PTEN siRNA. Dots represent individual events (cells), from a population of 10000 events analyzed by flow cytometry. Silencing of PTEN expression in $c-j n^{-1-}$ cells resulted in reduction of cell death, which was comparable to that observed with nutrient-deprived wild-type cells (upper panel). There were no significant changes in cell death when cells were cultured in complete $(10 \%)$ medium. Lower panel indicates average values $(P<0.01)$

tended to express higher levels of PTEN (Panc-48, AsPC-1 and Capan-1) (Figure 6a), suggesting an inverse correlation between c-Jun and PTEN levels in cancer cells. However, there was no correlation between the status of p53 and PTEN in these cell lines (Figure 6a). Immunoblot analysis indicated detectable expression of p53 in all but in the p53 null AsPC-1 cells, although only Panc-48 and HEK293 cells have been reported to express unmutated p53. ${ }^{31,32}$ The other cell lines carry various mutations in the p53 gene. ${ }^{31,33}$ 

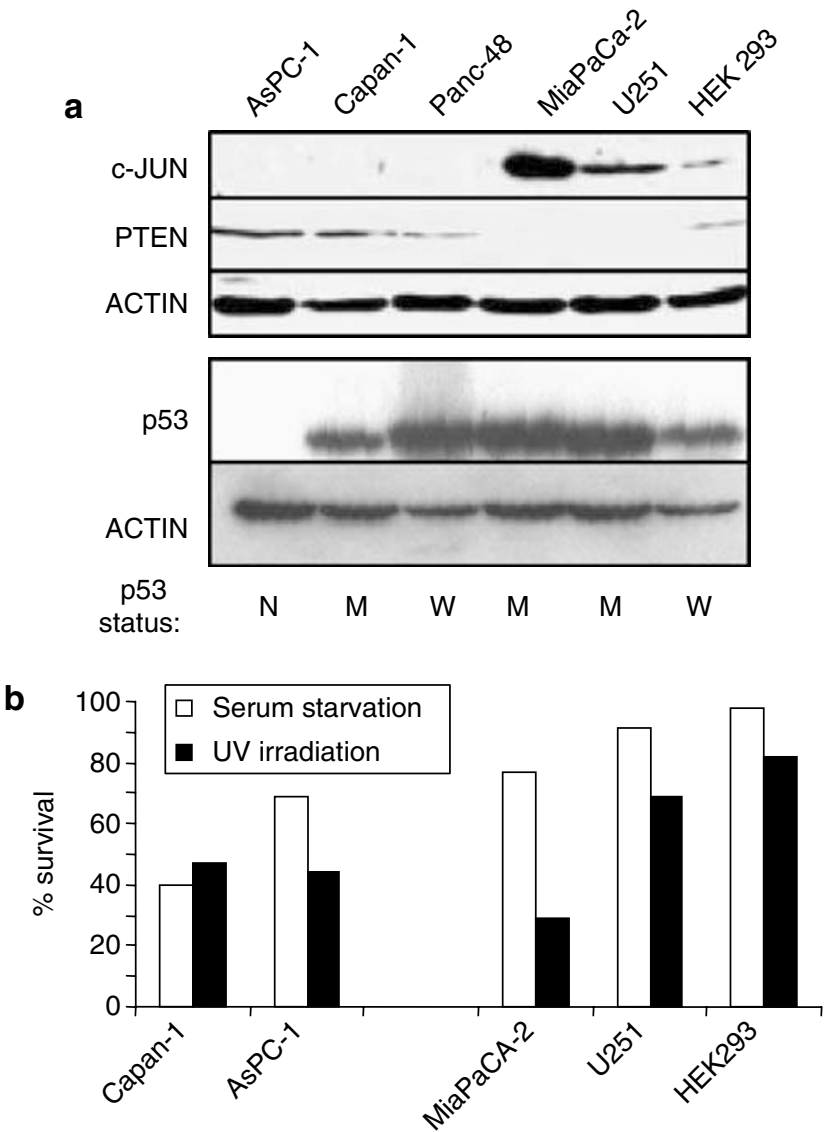

Figure 6 Inverse correlation between c-Jun levels and PTEN levels and cell survival in human cancer cells. (a) Immunoblot analysis of c-Jun, PTEN and p53 levels in several human pancreatic cancer cell lines (Panc-48, AsPC-1, Capan-1 and MiaPaCa-2), a glioblastoma cell line (U251) and transformed kidney epithelial cells (HEK293). Actin levels shows loading control. Status of $p 53$ gene in each cell line is indicated below. N: p53 null; M: mutant p53; W: wild type, unmutated p53. (b) Cell survival was analyzed in the above cells which were either UV irradiated $(40 \mathrm{~J} /$ $\mathrm{m}^{2}$ ) or cultured in nutrient-deprived medium (serum starvation) for $48 \mathrm{~h}$. Cell survival was determined as a percentage of surviving cells compared to untreated cells at $48 \mathrm{~h}$

We further evaluated if PTEN and c-Jun levels would correlate with cellular survival of these cell lines, upon exposure to stress signals such as UV irradiation and serum deprivation. Both Capan-1 and AsPC-1 cells, which had the highest levels of PTEN (Figure 6a), had the lowest survival rates in response to both UV irradiation and nutrient deprivation (Figure 6b). By contrast, MiaPACA-2, U251 and HEK293 cells that expressed the lowest levels of PTEN and highest levels of $\mathrm{C}$-Jun (Figure 6a) had the highest survival rate (Figure $6 \mathrm{~b}$ ). Thus, it appears that the levels of PTEN in these tumor cell lines are correlated with cellular survival and inversely correlated with c-Jun levels.

\section{Discussion}

c-Jun is an enigmatic protein that is involved in promoting both apoptosis and cellular proliferation/survival. ${ }^{1,2}$ Although several molecular targets of c-Jun regulating cellular proliferation and apoptosis have been documented, the mechanisms, if any, by which c-Jun contributes to cellular survival have not been elucidated. The data presented here identify PTEN as a target for c-Jun-mediated suppression in regulating cellular survival.

c-Jun is hyperexpressed in many human cancers and has been shown to be associated with increased tumorigenecity in many mouse models of cancer. ${ }^{1,5,6,34}$ Moreover, absence of c-Jun affects liver tumor formation in vivo in mice due to elevated apoptosis, ${ }^{14}$ highlighting a crucial role for c-Jun in regulating cellular survival leading to cancer. Albeit c-Jun has been shown to activate cyclin D1, which is required for progression of the cell cycle, and negatively regulate the tumor-suppressive effects of p53, ${ }^{11,12}$ it is not entirely clear if these mediators alone are sufficient for enhanced growth. Thus, the data presented here identify a novel target for c-Jun that is involved in regulating cellular survival. Moreover, the trend indicating an inverse correlation between c-Jun and PTEN, as well as the positive correlation between PTEN levels and cellular survival in several human cancer cell lines is entirely consistent with a pro-oncogenic role for c-Jun and tumor-suppressive role for PTEN in cancer development.

PTEN is also frequently mutated in human cancers, thereby leading to the loss of its tumor suppressive functions. ${ }^{25,35,36}$ Moreover, several positive regulators of PTEN such as p53 are also mutated in cancers, ${ }^{37}$ thereby indirectly resulting in lack of PTEN activation. Besides, PTEN expression was also silenced in the absence of any mutations in many adenocarcinoms of the breast and pancreatic cancers, suggesting that several mechanisms may contribute to the silencing of PTEN expression and that there may be other novel and yet unidentified pathways that may regulate its expression. ${ }^{30,38}$ In this respect, it was recently demonstrated that $\mathrm{DJ}-1$ is a novel negative regulator of PTEN that is often overexpressed in cancers. ${ }^{39}$ Together with the data presented here, it is increasingly apparent that PTEN expression could also be negatively regulated by proto-oncogenes such as c-Jun, thereby contributing to enhanced cell survival and eventual cancer formation. In this respect, it would be interesting to evaluate if other proto-oncogenes such as Ras could also suppress PTEN expression.

The Akt pathway, which is a crucial cell survival pathway that is often activated in many cancers owing to various mechanisms, ${ }^{26}$ is under the negative control of PTEN. Mutations leading to the loss of PTEN function have been shown to deregulate the Akt pathway, thereby leading to uncontrolled cellular growth. ${ }^{26}$ Our results indicate that consistent with a decrease in PTEN levels upon c-Jun induction, the Akt pathway is activated, correlating with cellular survival. Hence, it is conceivable that c-Jun potentiates cellular survival via PTEN and through the Akt pathway. Nonetheless, we cannot exclude the possibility that c-Jun also directly regulates the Akt survival pathway independent of PTEN.

Mechanistically, c-Jun may be directly involved in the negative regulation of PTEN expression. EMSA assays indicated that c-Jun is bound to the PF-1 sequences found in the $5^{\prime}$ flanking region of the PTEN promoter, which was similarly shown to be responsible for c-Jun-mediated suppression of p53 expression. ${ }^{11}$ This binding was specific as it could be supershifted by an antibody against c-Jun. Of note 
also is that the PF-1 site is about $19 \mathrm{~kb}$ away from the transcription start site. A survey of genes whose expression is suppressed by $\mathrm{c}$-Jun reveals that they contain similar PF-1 sites in the $5^{\prime}$ upstream sequences. This has been demonstrated for $\mathrm{p} 53,{ }^{11}$ and a PF-1 site is also found at two sites $(-16179$ and -22831 from transcription start in mfas and several sites in hfas) in the $5^{\prime}$ sequences of the fas gene (data not shown). Therefore, it is possible that c-Jun may employ these sites to suppress gene expression, although the precise mechanism by which c-Jun, via the PF-1 site, regulates PTEN expression needs further investigation. We had also attempted to immunoprecipitate c-Jun on the PF-1 sites on PTEN $5^{\prime}$ sequences in the native chromatin structures. However, we have not been able to successfully PCR out the region around the PF-1 site on the PTEN $5^{\prime}$ sequences, owing to the high GC content (data not shown). Nonetheless, it is evident from the genetic data presented from $c$-jun ${ }^{-1-}$ cells that c-Jun is indeed required for PTEN suppression.

It is also interesting to note that c-Jun-mediated PTEN suppression is not dependent on the status of p53. c-Jun was shown to suppress p53 through PF-1 sites. ${ }^{11}$ Hence, we could envisage that the induction of c-Jun would lead to p53 suppression, thereby leading to decrease in PTEN levels. However, our data using several human cell lines indicate that silencing of c-Jun resulted in an increase in PTEN levels independent of the p53 status. Furthermore, the status of p53 did not correlate with PTEN levels, in contrast to c-Jun, which was inversely correlated to PTEN levels in several human cancer cell lines. Moreover, cell survival in these cells also positively correlated with PTEN levels and inversely with C-Jun levels, but not with p53 levels or status, further demonstrating that c-Jun-dependent PTEN suppression can occur independent of p53. It is thus possible that during tumor progression, both p53 inactivation and increase in c-Jun levels can independently work together to decrease PTEN levels, thereby promoting cell growth.

In conclusion, our results demonstrate that c-Jun is a negative regulator of PTEN, leading to upregulation of the Akt survival pathway and thereby contributing to cellular survival. As c-Jun is overexpressed in many cancers, it thus presents a novel point for therapeutic intervention in cancers without mutations in PTEN or its regulators.

\section{Materials and Methods}

Cell lines, plasmids and transfections. All cell lines used in this study were cultured in 10\% fetal bovine serum, nonessential amino acids, L-Glutamine, sodium pyruvate, and antibiotics containing DMEM as described. ${ }^{11}$ Cells were deprived of nutrients by being cultured in $0.1 \%$ fetal bovine serum containing medium without other amino-acids and nutrients.

The inducible c-Jun expression vector was generated by cloning the c-Jun cDNA into pRetroTetOff vector (Clontech, Mountain View, CA, USA), and was stably transfected into NIH3T3 or $c-j$ ju $^{-1-}$ cells. Stable cell lines were selected on puromycin $(2 \mu \mathrm{g} / \mathrm{ml})$ and tetracycline $(1 \mu \mathrm{g} / \mathrm{ml})$ for $2-3$ weeks before individual clones were picked and propagated further. Individual clones were screened for $c$-Jun expression in the absence or presence of tetracycline.

$c-j u n^{-/-}$cells were infected with retroviral particles encoding wild-type c-Jun or the phospho-mutant c-Jun in which the serines 63 and 73 residues have been mutated to alanines (referred to as JunAA), or empty viral particles (pBabe), as described. ${ }^{11,12}$ Cells were stably selected on puromycin $(2 \mu \mathrm{g} / \mathrm{ml})$ for $2-3$ weeks and $\mathrm{c}$-Jun expression was determined by immunoblotting.

Cancer cell lines used in this study include Panc-48, AsPC-1, Capan-1 and MiaPaCa-2 (pancreatic cells); U251 (glioblastoma cell line) and HEK293 (transformed kidney epithelial cell), which have been described previously. ${ }^{30}$ The p53 status in these cells lines have been reported previously. ${ }^{31-33}$ Other human cells lines used in this study include the $\mathrm{H} 1299$ lung cancer cell line, MCF-7 breast cancer cell line and the SAOS2 and U2OS osteosarcoma cell line, which have been described. ${ }^{40}$

BrdU labeling was performed with $100 \mu \mathrm{M}$ of BrdU for $1.5 \mathrm{~h}$ to determine the percentage of cells in Sphase and analyzed with anti-BrdU FITC statining (Boehringer Mannheim, Ingelheim, Germany) by flow cytometry, as described. ${ }^{4}$

Transfection experiments were performed using Lipofectamine PLUS-Reagent, as per the manufacturer's instructions (Invitrogen, Carlsbad, CA, USA) and as described. ${ }^{40}$ Total amount of transfected DNA were equalized with appropriate amounts of pCDNA3 vector in all cases. Cells were collected $48 \mathrm{~h}$ after transfection and cell extracts were prepared and used for immunoblots, luciferase assays and RT-PCR analysis.

c-Jun small interfering RNA (siRNA) (5'-AAC CTC AGC AAC TTC AAC CCA-3') and PTEN siRNA (5'-GTT AGC AGA AAC AAA AGG AGA-3' and $5^{\prime}$-AAG ATC TTG ACC AAT GGC TAA-3') were transfected into cells using TransMessenger Transfection Reagent as per the manufacturer's instruction (Qiagen, Hilden, Germany).

Luciferase reporter assays. Cells were transfected with $0.1-0.5 \mu \mathrm{g}$ of the expression plasmids indicated in the figure legends, along with $0.5 \mu \mathrm{g}$ of the various PTEN promoter reporter constructs which have been previously described. ${ }^{28,29}$ The $10 \times$ PF-1 synthetic construct was generated by molecular cloning using a synthetic oligonuclietide which contains $10 \times$ the PF-1 sequence (i.e. TGACTCT) in tandem. This oligonucleotide was cloned in the PGL-3 basic luciferase reporter vector and sequenced for verification before use. For normalizing control, $0.5 \mu \mathrm{g}$ of plasmid encoding the $\beta$-galactosidase gene was co-transfected into each well in all transfection experiments. Cells were collected at $48 \mathrm{~h}$ post-transfection and luciferase assays were performed as described. ${ }^{28,40}$

RNA analysis. Total RNA was prepared from cells using TRIZOL Reagent (Invitrogen) as per the manufacturer's instructions. Of total RNA, $3 \mu \mathrm{g}$, were converted into single-strand cDNA using Superscript II (Invitrogen) as per the manufacturer's instructions. Semiquantitative reverse-transcriptase (RT)-PCR analysis of c-Jun, PTEN, p53 and GAPDH was performed, using the following primers: c-Jun (c-Jun forward: GGA AAC GAC CTT CTA TGA CGA T; c-Jun rev.: AAT GTT TGC AAC TGC TGC GT), PTEN (PTEN forward: GCCATCATCAAAGAGATCGTT; PTEN rev.: GGATCAGAGTCAGTGG) and GAPDH (GAPDH forward: ACCCCTTCATTGACCTCAAC; GAPDH rev:: CAGCGCCAGTAGAGGCAG). Under the following conditions: initial $94^{\circ} \mathrm{C}$ for $3 \mathrm{~min}$, follow by cycling $94^{\circ} \mathrm{C}$ for $50 \mathrm{~s}, 52^{\circ} \mathrm{C}$ for $50 \mathrm{~s}$ and $72^{\circ} \mathrm{C}$ for $1 \mathrm{~min}$. All PCR conditions were optimized such that the PCR product was detected in the logarithmic phase during the increase in cycle number (data not shown).

Quantitative real-time PCR was performed with SYBR ${ }^{\mathbb{R}}$ Green quantitative PCR kit (Qiagen) for GAPDH (primer sequence: $5^{\prime}$-ATCTTCTTGTGCAGTGCCAG-3' and $5^{\prime}$-GTAGTTGAGGTCAATGAAGG- ${ }^{\prime}$ ) and PTEN (primer sequence: $5^{\prime}$ TTGAAGACCATAACCCACC $3^{\prime}$ and $5^{\prime}$ ACCAGTCCGTCCCTTTCC $3^{\prime}$ ). mRNA abundance of individual gene was calculated against a standard curve of know amount of purified CDNA of each gene. Expression of PTEN was then normalized with GAPDH.

Immunoblot analysis. Immunoblot analysis was performed essentially as described, ${ }^{4}$ using the following antibodies: anti-c-Jun (H-79; Santa Cruz, CA, USA), anti-PTEN (Cell Signaling), p53 (CM-1, Novacastro, Newcastle, UK), anti-AKT and phospho-AKT (Ser 473; Cell Signaling), anti-Bad and phospho-Bad (Cell Signaling, Beverly, MA, USA), anti-FKHR and phospho-FKHR (Cell Signaling), anti-mTOR and phospho-mTOR (Cell Signaling) and antiactin (Sigma, St. Louis, MO, USA).

Cell death assays. Two independent cell death assays were employed in this study, namely PI exclusion and annexin-V staining. For PI exclusion, cells were harvested and washed once in PBS. Cell suspension was briefly incubated with $50 \mu \mathrm{g} / \mathrm{ml} \mathrm{PI}$ and immediately analyzed by flow cytometry to detected $\mathrm{PI}^{+}$cells, which represent the dead population. To detect annexin- $\mathrm{V}^{+}$cells, cells were incubated with FITC-conjugated annexin-V (BD biosciences, San Jose, CA, USA) and $50 \mu \mathrm{g} / \mathrm{ml} \mathrm{PI}$ in binding buffer (10 mM HEPES, pH 7.4; $0.14 \mathrm{M} \mathrm{NaCl} ; 2.5 \mathrm{mM}$ $\mathrm{CaCl}_{2}$ ) for $15 \mathrm{~min}$ in the dark at room temperature. Cells were analyzed by flow cytometry immediately after incubation. 
Cell death was analyzed subsequent to c-Jun induction for $48 \mathrm{~h}$ in the absence or presence of $\mathrm{CHX}(1 \mu \mathrm{g} / \mathrm{ml})$. Moreover, cells were treated with cisplatin $(25 \mathrm{uM})$, sorbitol, $(0.15 \mathrm{M})$, UV irradiation $\left(40 \mathrm{~J} / \mathrm{m}^{2}\right)$, hydrogen peroxide $(1 \mathrm{mM})$ or nutrient deprived $(0.1 \%$ serum $)$ for $48 \mathrm{~h}$ as indicated in figure legends before analysis of cell death.

siRNA-transfected cells were cultured in nutrient deprived or complete medium $16 \mathrm{~h}$ post-transfection for another $48 \mathrm{~h}$ before cell death analysis.

Electromobility-shift assays. Nuclear extracts were prepared by standard procedures and gel retardation assays were performed using $10 \mu \mathrm{g}$ of nuclear extracts, which were incubated on ice for $15 \mathrm{~min}$ in $15 \mu \mathrm{l}$ of buffer containing $10 \mathrm{mM}$ Tris ph7.4, $50 \mathrm{mM} \mathrm{NaCl}, 1 \mathrm{mM}$ EDTA pH8, $5 \%$ glycerol, $1 \mathrm{mM}$ DTT $1 \mu \mathrm{g}$ poly $(\mathrm{dl} \cdot \mathrm{dC}), 1 \mathrm{ng}$ of ${ }^{33} \mathrm{P}$-end-labeled PF-1 oligonucleotides: (5'ACAACAGTGA CTCTGTGCCTG $3^{\prime}$ ) and (5' CAGGCACAGAGTCACTGTTGT3'). A SP-1 oligonucleotide (5'-ATTCGATCGGGCGGCGAGC) (Promega, Madison, USA) was also used as a specific probe as well as a nonspecific competitor for the PF-1 probe. The specificity of PF-1-binding activity was determined using an excess $(50 \times)$ of either unlabeled PF-1 or SP-1 oligonucleotides, respectively, as competitors. DNA-protein complexes were separated by electrophoresis through a $5 \%$ native polyacrylamide gel, dried and visualized by autoradiography. Anti-phospho-c-Jun antibodies (KM-1, Santa Cruz) or a nonspecific p53 antibody (DO-1) was used in supershift assays.

Statistics. Unpaired student $t$-test provided by excel software was used to test statistical significance.

\section{Acknowledgements}

We thank Dr Axel Behrens for critical reading of the manuscript. This work was supported by the generous funding from the National Medical Research Council of Singapore (NMRC) and Biomedical Research Council of Singapore (BMRC) to KS. $\mathrm{KH}$ was partially supported by a postdoctoral fellowship from the Austrian Science Fund (FWF). Correspondence and requests for materials should be addressed to KS at cmrksb@nccs.com.sg.

1. Eferl R, Wagner EF. AP-1: a double-edged sword in tumorigenesis. Nat Rev Cancer 2003; 3: 859-868.

2. Shaulian E, Karin M. AP-1 as a regulator of cell life and death. Nat Cell Biol 2002; 4: E131E136.

3. Behrens A, Sibilia M, Wagner EF. Amino-terminal phosphorylation of c-Jun regulates stress-induced apoptosis and cellular proliferation. Nat Genet 1999; 21: 326-329.

4. Sabapathy K, Hochedlinger K, Nam SY, Bauer A, Karin M, Wagner EF. Distinct roles for JNK1 and JNK2 in regulating JNK activity and c-Jun-dependent cell proliferation. Mol Cell 2004; 15: 713-725.

5. Papachristou DJ, Batistatou A, Sykiotis GP, Varakis I, Papavassiliou AG. Activation of the JNK-AP-1 signal transduction pathway is associated with pathogenesis and progression of human osteosarcomas. Bone 2003; 32: 364-371.

6. Wang $\mathrm{H}$, Birkenbach M, Hart J. Expression of Jun family members in human colorecta adenocarcinoma. Carcinogenesis 2000; 21: 1313-1317.

7. Morishima Y, Gotoh Y, Zieg J, Barrett T, Takano H, Flavell R et al. Beta-amyloid induces neuronal apoptosis via a mechanism that involves the c-Jun $\mathrm{N}$-terminal kinase pathway and the induction of Fas ligand. J Neurosci 2001; 21: 7551-7560.

8. Resnick L, Fennell M. Targeting JNK3 for the treatment of neurodegenerative disorders. Drug Discov Today 2004; 9: 932-939.

9. Eferl R, Sibilia M, Hilberg F, Fuchsbichler A, Kufferath I, Guertl B et al. Functions of c-Jun in liver and heart development. J Cell Biol 1999; 145: 1049-1061.

10. Liu Y, Lu C, Shen Q, Munoz-Medellin D, Kim H, Brown PH. AP-1 blockade in breast cance cells causes cell cycle arrest by suppressing G1 cyclin expression and reducing cyclindependent kinase activity. Oncogene 2004; 23: 8238-8246.

11. Schreiber M, Kolbus A, Piu F, Szabowski A, Mohle-Steinlein U, Tian J et al. Control of cell cycle progression by C-Jun is p53 dependent. Genes Dev 1999; 13: 607-619.

12. Wisdom R, Johnson RS, Moore C. c-Jun regulates cell cycle progression and apoptosis by distinct mechanisms. EMBO J 1999; 18: 188-197.

13. David JP, Sabapathy K, Hoffman O, Idarraga MH, Wagner EF. JNK1 modulates osteoclastogenesis through both c-Jun phosphorylation-dependent and -independen mechanisms. J Cell Sci 2002; 115: 4317-4325.

14. Eferl R, Ricci R, Kenner L, Zenz R, David JP, Rath M et al. Liver tumor development. c-Jun antagonizes the proapoptotic activity of p53. Cell 2003; 112: 181-192.
15. Kolbus A, Herr I, Schreiber M, Debatin KM, Wagner EF, Angel P. c-Jun-dependent CD95-L expression is a rate-limiting step in the induction of apoptosis by alkylating agents. Mol Cell Biol 2000; 20: 575-582

16. Raivich G, Bohatschek M, Da Costa C, Iwata O, Galiano M, Hristova M et al. The AP-1 transcription factor c-Jun is required for efficient axonal regeneration. Neuron 2004; 43: $57-67$.

17. Sabapathy K, Kallunki T, Schreiber M, David JP, Jochum W, Wagner EF et al. JNK2 is required for efficient T-cell activation and apoptosis but not for normal lymphocyte development. Curr Biol 1999; 9: 116-125.

18. Sabapathy K, Jochum W, Hochedlinger K, Chang L, Karin M, Wager EF. Defective neural tube morphogenesis and altered apoptosis in the absence of both JNK1 and JNK2. Mech Dev 1999; 89: 115-124.

19. Watson A, Eilers A, Lallemand D, Kyriakis J, Rubin LL, Ham J. Phosphorylation of c-Jun is necessary for apoptosis induced by survival signal withdrawal in cerebellar granule neurons. J Neurosci 1998; 18: 751-762.

20. Yang DD, Kuan CY, Whitmarsh AJ, Rincon M, Zheng TS, Davis RJ et al. Absence of excitotoxicity-induced apoptosis in the hippocampus of mice lacking the Jnk3 gene. Nature 1997; 389: 865-870.

21. Behrens A, Sabapathy K, Graef I, Cleary M, Crabtree GR, Wagner EF. Jun N-terminal kinase 2 modulates thymocyte apoptosis and T cell activation through c-Jun and nuclear factor of activated T cell (NF-AT). Proc Natl Acad Sci USA 2001; 98: 1769-1774.

22. Bossy-Wetzel E, Bakiri L, Yaniv M. Induction of apoptosis by the transcription factor c-Jun. EMBO J 1997: 16: 1695-1709.

23. Eichhorst ST, Muller M, Li-Weber M, Schulze-Bergkamen H, Angel P, Krammer PH. A novel AP-1 element in the CD95 ligand promoter is required for induction of apoptosis in hepatocellular carcinoma cells upon treatment with anticancer drugs. Mol Cell Biol 2000; 20: 7826-7837.

24. Putcha GV, Le S, Frank S, Besirli CG, Clark K, Chu B et al. JNK-mediated BIM phosphorylation potentiates BAX-dependent apoptosis. Neuron 2003; 8: 899-914.

25. Sun $\mathrm{H}$, Lesche R, Li DM, Liliental J, Zhang $\mathrm{H}$, Gao J et al. PTEN modulates cell cycle progression and cell survival by regulating phosphatidylinositol 3, 4, 5, -trisphosphate and Akt/protein kinase B signaling pathway. Proc Natl Acad Sci USA 1999; 96 : 6199-6204.

26. Marte BM, Downward J. PKB/Akt: connecting phosphoinositide 3-kinase to cell survival and beyond. Trends Biochem Sci 1997; 22: 355-358.

27. Stambolic V, MacPherson D, Sas D, Lin Y, Snow B, Jang $Y$ et al. Regulation of PTEN transcription by p53. Mol Cell 2001; 8: 317-325.

28. Virolle T, Adamson ED, Baron V, Birle D, Mercola D, Mustelin T et al. The Egr-1 transcription factor directly activates PTEN during irradiation-induced signalling. Nat Cell Biol 2001; 3: 1124-1128.

29. Han B, Dong Z, Liu Y, Chen Q, Hashimoto K, Zhang JT. Regulation of constitutive expression of mouse PTEN by the $5^{\prime}$-untranslated region. Oncogene 2003; 22: 53255337.

30. Asano T, Yao Y, Zhu J, Li D, Abbruzzese JL, Reddy SA. The PI 3-kinase/Akt signaling pathway is activated due to aberrant Pten expression and targets transcription factors NF-kappaB and c-Myc in pancreatic cancer cells. Oncogene 2004; 23: $8571-8580$

31. Bouvet M, Bold RJ, Lee J, Evans DB, Abbruzzese JL, Chiao PJ et al. Adenovirus-mediated wild-type $\mathrm{p} 53$ tumor suppressor gene therapy induces apoptosis and suppresses growth of human pancreatic cancer. Ann Surg Oncol 1998; 5: 681-688.

32. Quinones A, Rainov NG. Identification of genotoxic stress in human cells by fluorescent monitoring of p53 expression. Mutat Res 2001; 494: 73-85.

33. Shono T, Tofilon PJ, Schaefer TS, Parikh D, Liu TJ, Lang FF. Apoptosis induced by adenovirus-mediated p53 gene transfer in human glioma correlates with site-specific phosphorylation. Cancer Res 2002; 62: 1069-1076.

34. Wang ZQ, Liang J, Schellander K, Wagner EF, Grigoriadis AE. C-fos-induced osteosarcoma formation in transgenic mice: cooperativity with c-jun and the role of endogenous c-fos. Cancer Res 1995; 55: 6244-6251.

35. Cantley LC, Neel BG. New insights into tumor suppression: PTEN suppresses tumor formation by restraining the phosphoinositide 3-kinase/AKT pathway. Proc Natl Acad Sci USA 1999; 96: 4240-4245.

36. Eng C, Peacocke M. PTEN and inherited hamartoma-cancer syndromes. Nat Genet 1998; 19: 223.

37. Soussi T, Beroud C. Significance of TP53 mutations in human cancer: a critical analysis of mutations at $\mathrm{CpG}$ dinucleotides. Hum Mutat 2003; 21: 192-200.

38. Garcia JM, Silva J, Pena C, Garcia V, Rodriguez R, Cruz MA et al. Promoter methylation of the PTEN gene is a common molecular change in breast cancer. Genes Chromo Cancer 2004; 41: 117-124.

39. Kim RH, Peters M, Jang Y, Shi W, Pintilie M, Fletcher GC et al. DJ-1, a novel regulator of the tumor suppressor PTEN. Cancer Cell 2005; 7: 263-273.

40. Toh WH, Kyo S, Sabapathy K. Relief of P53-mediated telomerase suppression by P73. J Biol Chem 2005; 280: 17329-17338. 